\title{
Efficacy of an Innovative Aerosol Foam Formulation of Fixed Combination Calcipotriol plus Betamethasone Dipropionate in Patients with Psoriasis Vulgaris
}

\author{
Catherine Queille-Roussel • Martin Olesen • \\ John Villumsen · Jean-Philippe Lacour
}

Published online: 24 February 2015

(c) The Author(s) 2015. This article is published with open access at Springerlink.com

\begin{abstract}
Background and Objective The antipsoriatic effect of an innovative aerosol foam formulation of fixed combination calcipotriol $50 \mu \mathrm{g} / \mathrm{g}$ (as hydrate; Cal) and betamethasone $0.5 \mathrm{mg} / \mathrm{g}$ (as dipropionate; BD) was explored in order to compare the effect with that of the first-line treatment Cal/ BD ointment.

Methods This was a Phase IIa, single-centre, investigatorblinded, exploratory study, with intra-individual comparison using a modified psoriasis plaque test. Patients were treated once daily (6 days/week) for 4 weeks with $\mathrm{Cal} / \mathrm{BD}$ foam, Cal/BD ointment, BD foam and Cal/BD foam vehicle, randomized to four plaque test sites $\left(5 \mathrm{~cm}^{2}\right.$ each). The primary efficacy endpoint was change in total clinical score (TCS; sum of erythema, scaling and lesional thickness). Secondary endpoints included ultrasonographic changes in total skin thickness and echo-poor band thickness, and adverse events.

Results Twenty-four patients, median age 52.5 years (range 21-75), completed this study. At week 4, test sites treated with $\mathrm{Cal} / \mathrm{BD}$ foam had a significantly greater
\end{abstract}

Clinical trial registration: NCT01347255.

C. Queille-Roussel $(\bowtie) \cdot$ J.-P. Lacour

Centre de Pharmacologie Clinique Appliquée à la Dermatologie,

Hôpital L'Archet 2, 06202 Nice Cedex 3, France

e-mail: catherine.queille-roussel@skinpharma.fr

M. Olesen · J. Villumsen

LEO Pharma A/S, Ballerup, Denmark

J.-P. Lacour

Service de Dermatologie, University Hospital of Nice,

Nice, France decrease in mean $( \pm S D)$ TCS $(-6.00 \pm 1.27)$ versus those treated with $\mathrm{Cal} / \mathrm{BD}$ ointment $(-5.25 \pm 1.78$; difference $-0.75 ; 95 \% \mathrm{CI}-1.46$ to $-0.04 ; p=0.038)$, BD foam $(-4.96 \pm 1.85 ;$ difference $-1.04 ; 95 \%$ CI -1.75 to $-0.33 ; p=0.005)$ or foam vehicle $(-1.88 \pm 1.12$; difference $-4.13 ; 95 \% \mathrm{CI}-4.83$ to $-3.42 ; p<0.001)$. Total skin thickness and echo-poor band thickness of Cal/BD foam-treated sites were reduced to a greater extent than those treated with comparators. Eleven patients reported 17 adverse events, the most frequent being headache (five patients). There were no lesional/perilesional adverse events or adverse drug-related events.

Conclusions $\mathrm{Cal} / \mathrm{BD}$ foam demonstrated a significant improvement in antipsoriatic effect over Cal/BD ointment, BD foam and foam vehicle alone.

\section{Key Points}

An innovative aerosol foam formulation of a fixed combination of calcipotriol $50 \mu \mathrm{g} / \mathrm{g}$ (as hydrate) and betamethasone $0.5 \mathrm{mg} / \mathrm{g}$ (as dipropionate) has been developed to provide a highly effective topical psoriasis treatment delivered in a more patientacceptable vehicle.

This aerosol foam formulation demonstrated a significant improvement in clinical signs of psoriatic lesions compared with the fixed combination ointment, betamethasone aerosol foam and aerosol foam vehicle alone.

The aerosol foam formulation may represent a more efficacious alternative to current first-line topical treatment options for patients with psoriasis vulgaris. 


\section{Introduction}

Psoriasis vulgaris (plaque psoriasis) is a chronic, inflammatory disorder, typically with well-demarcated, erythematous, thickened, scaly plaques on the body and scalp [13]. The World Health Organization (WHO) recognizes that psoriasis is a painful and debilitating disease [4] associated with serious co-morbidities, such as cardiovascular disease, diabetes mellitus and psoriatic arthritis [5, 6], as well as a number of psychosocial disorders, including depression [6]. As such, the negative impact of psoriasis on patients' quality of life can be considerable [6,7].

Topical therapy remains the mainstay of psoriasis treatment, with more than $80 \%$ of patients being able to manage their psoriasis with topicals alone $[8,9]$. Guidelines recommend the topical use of corticosteroids and vitamin D analogues (be it as monotherapies used in combination or as fixed combinations) as first-line treatment for psoriasis $[8,9]$. The fixed combination of calcipotriol $50 \mu \mathrm{g} / \mathrm{g}$ (as hydrate; $\mathrm{Cal}$ ) and betamethasone $0.5 \mathrm{mg} / \mathrm{g}$ (as dipropionate; BD) has demonstrated increased efficacy and reduced side effects compared with either of the active ingredients when used as monotherapies [10-12]. Furthermore, the presence of calcipotriol may also provide an additive, steroid-sparing effect on betamethasone dipropionate [3]. This combination is currently available in gel or ointment formulations (Taclonex ${ }^{\circledR} /$ Daivobet $^{\circledR} /$ Dovobet $^{\circledR}$ ), both of which are first-line treatment options for patients with mild-to-moderate psoriasis vulgaris $[8,9]$.

An innovative aerosol foam formulation of the $\mathrm{Cal} / \mathrm{BD}$ fixed combination has now been developed to improve topical treatment of psoriasis vulgaris. In this exploratory study, the antipsoriatic effect of $\mathrm{Cal} / \mathrm{BD}$ aerosol foam was compared with that of the established fixed combination Cal/ $\mathrm{BD}$ ointment, as well as $\mathrm{BD}$ aerosol foam and $\mathrm{Cal} / \mathrm{BD}$ aerosol foam vehicle, using a modified version of the psoriatic plaque test developed by Dumas and Scholtz [12-15].

\section{Methods}

\subsection{Patients}

Patients were at least 18 years of age, diagnosed with psoriasis vulgaris of the body with psoriatic plaques of a total size suitable for application of four different treatments. Patients were required to have stable disease and plaques with a total clinical score [TCS; sum of scores of erythema, scaling and lesional thickness (each scored from 0 to 3)] of 4-9 inclusive and a score for each individual component of $\geq 1$. Disease stability was based on TCS component scores measured at a screening visit (within
3 weeks of start of treatment) and baseline; disease was considered stable if the change in score for any single symptom was $<1$ point. Exclusion criteria included: treatment with etanercept within 4 weeks, adalimumab, alefacept or infliximab within 2 months, or ustekinumab within 4 months; any other biological or systemic therapy within 4 weeks or five half-lives (whichever was longer); psoralen combined with ultraviolet A or Grenz ray therapy within 4 weeks or ultraviolet B therapy within 2 weeks; potent or very potent (WHO class III-IV) corticosteroids within 4 weeks; or emollients within 1 week. Topical antipsoriatic treatment of the scalp and/or facial psoriasis with WHO class I-II corticosteroids was allowed within 2 weeks of start of study treatment.

\subsection{Study Design and Objectives}

This was a single-centre, investigator-blinded, vehiclecontrolled, 4-week exploratory study (ClinicalTrials.gov identifier: NCT01347255) with intra-individual comparison, in which the following investigational products were assessed: Cal/BD aerosol foam (LEO Pharma, Denmark), $\mathrm{Cal} / \mathrm{BD}$ ointment $\left(\right.$ Taclone ${ }^{\circledR} /$ Daivobet $^{\circledR} /$ Dovobet $^{\circledR} ;$ LEO Pharma, Denmark), BD aerosol foam and $\mathrm{Cal} / \mathrm{BD}$ aerosol foam vehicle. Each patient received simultaneous application (by a study nurse/assistant) of all investigational products to four predetermined target plaques on their arms, legs or trunk, applied once daily (6 days per week, excluding Sundays) for 4 weeks. Per patient, the test application site for each product was determined according to random assignment. Test sites $\left(5 \mathrm{~cm}^{2}\right)$ were delimited with a disposable circular adhesive (replaced twice a week) and outlined using an indelible marker. The minimum distance allowed between two test sites was $2 \mathrm{~cm}$. For application of the aerosol foam products, $50 \mathrm{mg}$ of product was sprayed directly onto the appropriate test site, using a circular template. $\mathrm{Cal} / \mathrm{BD}$ ointment was applied using an Eppendorf Combitip $^{\circledR}$ (Eppendorf AG, Hamburg, Germany). Each product was gently massaged into the test sites with gloved fingers and then non-occlusive gauze was applied until the next treatment application.

The study was conducted in accordance with the ethical principles of the Declaration of Helsinki and good clinical practice guidelines. The study protocol was approved by the independent ethics committee of the investigational site. All patients provided written informed consent before enrolment.

The primary objective was to evaluate the antipsoriatic effect of $\mathrm{Cal} / \mathrm{BD}$ aerosol foam compared with $\mathrm{Cal} / \mathrm{BD}$ ointment, BD aerosol foam and Cal/BD aerosol foam vehicle, using the modified psoriasis plaque test. The secondary objective was to obtain information on adverse events (AEs) for all investigational products. 


\subsection{Assessments}

Clinical and safety assessments were performed at baseline and then twice weekly on days 4, 8, 11, 15, 18, 22, 25 and 29. Test site severity of erythema, scaling and lesional thickness (using a 0-3 half-point grading scale) was assessed by the investigator after removal of the non-occlusive gauze and prior to treatment reapplication; a single investigator performed all clinical assessments. Ultrasound measurements were performed at baseline and once weekly (days 8, 15, 22 and 29) using a B scanner equipped with a 20-MHz transducer. At each time point, three B scans were made per test site. Safety and tolerability were assessed throughout the study by evaluating AEs and adverse drug reactions (ADRs).

\subsection{Statistical Analysis}

Twenty-four patients were required to achieve $80 \%$ power of rejecting the null hypothesis with a $5 \%$ significance level. The primary efficacy response was the change in TCS (range 0-9) from baseline to week 4. Secondary efficacy responses included change from baseline in TCS and its individual components (erythema, scaling and lesional thickness), and ultrasound-determined total skin thickness and echo-poor band thickness (a measure of superficial dermis inflammation), by visit. Efficacy endpoints were analysed by a two-way analysis of variance and are described using summary statistics. All significance tests are reported as two-sided with a $95 \%$ confidence interval (CI). All patients who received at least one dose of study treatment were included in the full (intent-to-treat) and safety analysis sets.

\section{Results}

\subsection{Patient Disposition and Demographics}

Between May and June 2011, 24 patients were enrolled in this study, two-thirds of whom were male (Table 1). All patients were exposed to all four investigational products, completed the study, and were included in the full and safety analysis sets.

\subsection{Efficacy}

\subsubsection{Clinical Assessment}

At week 4, there was a significantly larger decrease in mean [ \pm standard deviation (SD)] TCS for those test sites treated with $\mathrm{Cal} / \mathrm{BD}$ aerosol foam $(-6.00 \pm 1.27)$ compared with those treated with $\mathrm{Cal} / \mathrm{BD}$ ointment
Table 1 Patient demographics and baseline characteristics

\begin{tabular}{ll}
\hline Characteristic & Value \\
\hline Number of patients & 24 \\
Median (range) age, years & $52.5(21-75)$ \\
Males, $n(\%)$ & $16(66.7)$ \\
Fitzpatrick skin type ${ }^{a} n(\%)$ & $1(4.2)$ \\
Type II & $23(95.8)$ \\
Type III & $19.5(3-49)$ \\
Median (range) disease duration, years & $7.07 \pm 0.78$ \\
Mean \pm standard deviation total clinical score & \\
a Type II: white, always burns, tans minimally; Type III: white, burns \\
moderately, tans gradually (light brown) \\
b Sum of three scores (erythema, scaling, lesional thickness)
\end{tabular}

$(-5.25 \pm 1.78 ;$ difference $-0.75 ; 95 \% \mathrm{CI}-1.46$ to $-0.04 ; p=0.038)$, BD aerosol foam $(-4.96 \pm 1.85$; difference $-1.04 ; 95 \% \mathrm{CI}-1.75$ to $-0.33 ; p=0.005)$ or $\mathrm{Cal} / \mathrm{BD}$ aerosol foam vehicle $(-1.88 \pm 1.12$; difference $-4.13 ; 95 \% \mathrm{CI}-4.83$ to $-3.42 ; p<0.001)$. A continuous improvement in TCS was observed for all active treatments throughout the study, with the mean decrease in TCS being consistently larger with $\mathrm{Cal} / \mathrm{BD}$ aerosol foam compared with all other products, from the second on-treatment assessment time point (day 8) until the end of the study (Fig. 1a). Similarly, mean changes $( \pm S D)$ in the TCS components from baseline to week 4 were also found to be higher for those test sites treated with $\mathrm{Cal} / \mathrm{BD}$ aerosol foam (erythema $-1.75 \pm 0.71$; scaling $-2.13 \pm 0.47$; lesional thickness $-2.13 \pm 0.45)$ than for those treated with $\mathrm{Cal} /$ $\mathrm{BD}$ ointment $(-1.50 \pm 0.66 ;-2.02 \pm 0.56 ;-1.73 \pm$ 0.82 , respectively), $\mathrm{BD}$ aerosol foam $(-1.44 \pm 0.78$; $-2.02 \pm 0.58 ;-1.50 \pm 0.77)$ and $\mathrm{Cal} / \mathrm{BD}$ aerosol foam vehicle $\quad(-0.56 \pm 0.47 ; \quad-0.90 \pm 0.47 ; \quad-0.42 \pm 0.43$; Fig. 1b-d).

\subsubsection{Ultrasound Assessment}

Throughout this study, reductions in total skin thickness and echo-poor band thickness were consistently greater with $\mathrm{Cal} / \mathrm{BD}$ aerosol foam treatment compared with all other treatments. At week 4, treatment with $\mathrm{Cal} / \mathrm{BD}$ aerosol foam reduced the mean total skin thickness $( \pm \mathrm{SD})$ to a greater extent $(-0.81 \pm 0.41 \mathrm{~mm})$, although not significantly so, than with $\mathrm{Cal} / \mathrm{BD}$ ointment $(-0.62 \pm 0.37 \mathrm{~mm}$; difference, $-0.19 \mathrm{~mm} ; 95 \% \mathrm{CI}-0.40$ to $0.03 ; p=0.088$ ) or $\mathrm{BD}$ aerosol foam $(-0.66 \pm 0.42 \mathrm{~mm}$; difference, $-0.14 \mathrm{~mm}$; $95 \% \mathrm{CI}-0.36$ to $0.07 ; p=0.190)$, and significantly greater compared with $\mathrm{Cal} / \mathrm{BD}$ aerosol foam vehicle $(-0.23 \pm$ $0.30 \mathrm{~mm}$; difference, $-0.58 \mathrm{~mm} ; 95 \% \mathrm{CI}-0.79$ to -0.36 ; $p<0.001$; Fig. 2). Similarly, the mean reduction in echopoor band thickness at week 4 was consistently greater (but 

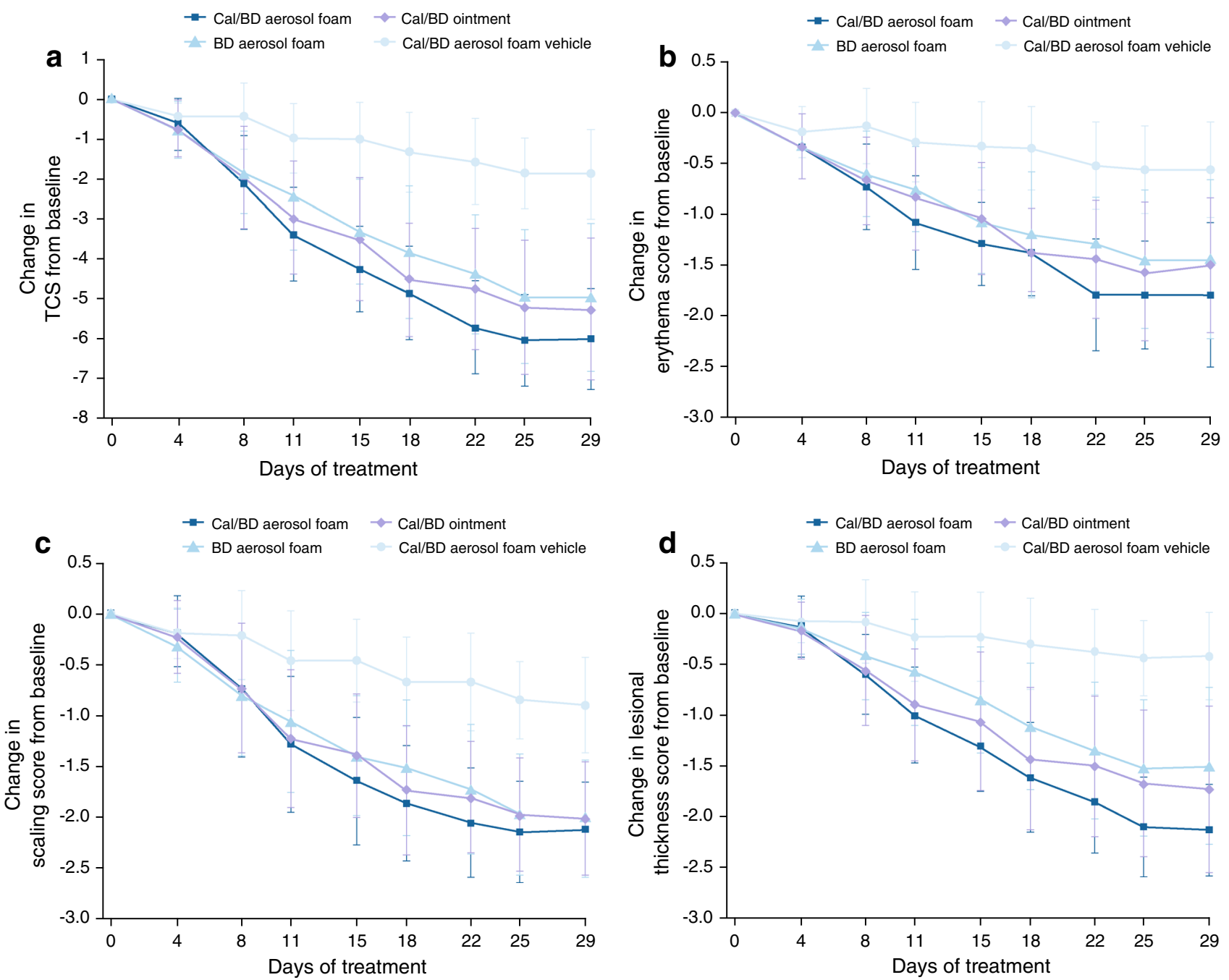

Fig. 1 Change from baseline (mean \pm standard deviation) in a TCS, and its components $\mathbf{b}$ erythema, $\mathbf{c}$ scaling, and $\mathbf{d}$ lesional thickness, to end of treatment. $B D$ betamethasone $0.5 \mathrm{mg} / \mathrm{g}$ (as dipropionate), Cal calcipotriol $50 \mu \mathrm{g} / \mathrm{g}$ (as hydrate), TCS total clinical score

again not significantly so) following treatment with $\mathrm{Cal} / \mathrm{BD}$ aerosol foam $(-0.57 \pm 0.21 \mathrm{~mm})$ than with $\mathrm{Cal} / \mathrm{BD}$ ointment $(-0.46 \pm 0.21 \mathrm{~mm}$; difference $-0.11 \mathrm{~mm} ; 95 \%$ CI -0.22 to $0.00 ; p=0.052)$, and was significantly greater compared with BD aerosol foam $(-0.45 \pm 0.25 \mathrm{~mm}$; difference $-0.12 \mathrm{~mm} ; 95 \% \mathrm{CI}-0.23$ to $-0.01 ; p=0.037)$ and $\mathrm{Cal} / \mathrm{BD}$ aerosol foam vehicle $(-0.12 \pm 0.20 \mathrm{~mm}$; difference $-0.44 \mathrm{~mm}$; $95 \% \mathrm{CI}-0.55$ to $-0.33 ; p<0.001$; Fig. 3).

\subsection{Safety and Tolerability}

Seventeen AEs were reported by 11 patients during this study, with the most common being headache $(n=5)$ and arthralgia $(n=3)$ (Table 2). There were no reports of serious AEs or ADRs and no withdrawals due to AEs.

\section{Discussion}

This 4-week exploratory study demonstrated significant improvement in antipsoriatic effect with the novel $\mathrm{Cal} /$ BD aerosol foam formulation compared with the Cal/BD ointment formulation, $\mathrm{BD}$ aerosol foam and $\mathrm{Cal} / \mathrm{BD}$ aerosol foam vehicle. The modified version of the psoriasis plaque test employed in this study is a quick, safe, information-rich and relatively low-cost method to evaluate the antipsoriatic effect of psoriasis treatments. It enables intra-individual comparisons and increases the probability of detection of clinically relevant differences despite the relatively short study period and limited sample size [16].

The improved efficacy of other foam preparations over conventional formulations of topical treatments in psoriasis has been demonstrated in several studies. For example, 


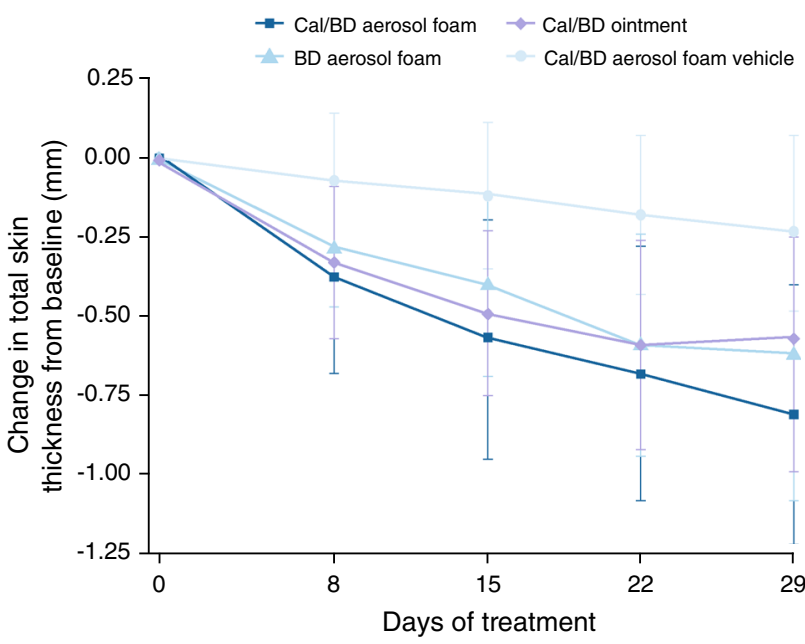

Fig. 2 Change from baseline (mean \pm standard deviation) in total skin thickness (assessed by ultrasonographic imagery) to end of treatment. $B D$ betamethasone $0.5 \mathrm{mg} / \mathrm{g}$ (as dipropionate), Cal calcipotriol $50 \mu \mathrm{g} / \mathrm{g}$ (as hydrate)

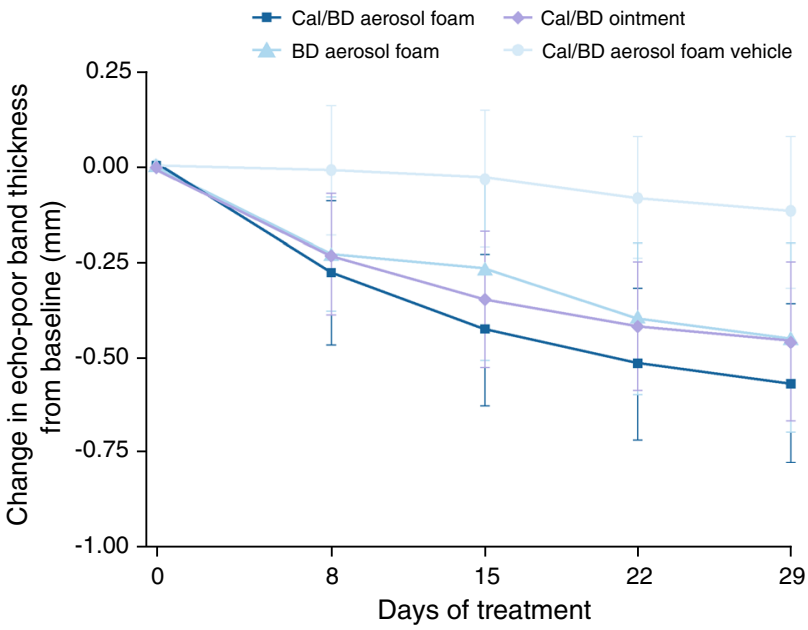

Fig. 3 Change from baseline (mean \pm standard deviation) in echopoor band thickness (assessed by ultrasonography) to end of treatment. $B D$ betamethasone $0.5 \mathrm{mg} / \mathrm{g}$ (as dipropionate), Cal calcipotriol $50 \mu \mathrm{g} / \mathrm{g}$ (as hydrate)

clobetasol propionate in a foam formulation is more effective than the cream and solution formulations in decreasing Psoriasis Area and Severity Index score [17]. Similarly, betamethasone valerate is more effective in improving psoriasis symptoms when delivered as foam versus lotion [18, 19]. In addition to their application advantage, foam vehicles have unique characteristics and properties that can be engineered to enhance topical drug delivery. Foam formulations of clobetasol propionate and betamethasone valerate absorb more rapidly into the skin, with greater total skin absorption than their respective comparison formulations, namely, clobetasol propionate solution and betamethasone valerate lotion
Table 2 Adverse events according to the Medical Dictionary for Regulatory Activities (MedDRA) primary system organ class and preferred term

\begin{tabular}{ll}
\hline Adverse event & Patients, $n(\%)^{\mathrm{a}}$ \\
\hline Nervous system disorders & $6(25.0)$ \\
Headache & $5(20.8)$ \\
Sciatica & $1(4.2)$ \\
Musculoskeletal and connective tissue disorders & $4(16.7)$ \\
Arthralgia & $3(12.5)$ \\
Back pain & $1(4.2)$ \\
Gastrointestinal disorders & $3(12.5)$ \\
Diarrhoea & $1(4.2)$ \\
Toothache & $2(8.3)$ \\
Infections and infestations & $2(8.3)$ \\
Gastroenteritis & $1(4.2)$ \\
Nasopharyngitis & $1(4.2)$ \\
Eye disorders & $1(4.2)$ \\
Conjunctivitis & $1(4.2)$ \\
General disorders and administration site & $1(4.2)$ \\
conditions & $1(4.2)$ \\
Pyrexia &
\end{tabular}

Classification according to MedDRA version 6.1

${ }^{a}$ Patients may have had more than one adverse event

[20]. Furthermore, using an in vitro skin permeation model, Huang et al. showed that foam vehicle delivers more clobetasol propionate than other formulations (solution, cream and lotion) and does so more efficiently [21]. Consistent with these findings, an in vitro study assessing skin penetration of the $\mathrm{Cal} / \mathrm{BD}$ aerosol foam demonstrated that the levels of diffusion of each active ingredient into a skin model were consistently higher for Cal/BD aerosol foam, with significantly higher steadystate levels of $\mathrm{Cal}$ and $\mathrm{BD}$, than $\mathrm{Cal} / \mathrm{BD}$ ointment [22].

As well as providing a highly effective treatment, optimizing drug delivery to the skin, the vehicle has also been designed to provide a better user experience - to be a more cosmetically acceptable preparation than current formulations. Treatment non-adherence has been recognized as an important and complex issue in disease management [2325]. For psoriasis treatment, the patient's preference for certain formulations and their perception of the efficacy of their treatment are key factors affecting adherence [26-29]. Psoriasis patients are less willing to adhere to their topical treatment if they find application to be cumbersome and time consuming [26, 27, 30], and comparisons of treatment vehicles have shown that patients prefer more cosmetically elegant formulations, such as foam vehicles, which are convenient and easy to use, thereby minimizing impact on daily life [31, 32]. 


\section{Conclusion}

In conclusion, this exploratory study has demonstrated a superior antipsoriatic effect with $\mathrm{Cal} / \mathrm{BD}$ aerosol foam compared with $\mathrm{Cal} / \mathrm{BD}$ ointment, $\mathrm{BD}$ aerosol foam and $\mathrm{Cal} / \mathrm{BD}$ aerosol foam vehicle. The aerosol foam formulation may represent a more efficacious and acceptable alternative to well-established, conventional formulations of $\mathrm{Cal} / \mathrm{BD}$.

Acknowledgments This study was sponsored by LEO Pharma. We thank Patrice Facy and Florence Préaud, both from LEO Pharma, for clinical trial management, and Magali Procacci Babled, from CPCAD, for study coordination. Medical writing support was provided by Zoë van Helmond, $\mathrm{PhD}$, from Mudskipper Business Ltd and funded by LEO Pharma. This paper was previously presented as a poster at ESDR 2014 and Fall CDC 2014.

Conflict of interest CQR and JPL have no conflicts of interest to declare. MO was an employee of LEO Pharma A/S at the time of this study. JV is an employee of LEO Pharma A/S.

Open Access This article is distributed under the terms of the Creative Commons Attribution Noncommercial License which permits any noncommercial use, distribution, and reproduction in any medium, provided the original author(s) and the source are credited.

\section{References}

1. Menter A, Gottlieb A, Feldman SR, et al. Guidelines of care for the management of psoriasis and psoriatic arthritis: section 1. Overview of psoriasis and guidelines of care for the treatment of psoriasis with biologics. J Am Acad Dermatol. 2008;58:826-50.

2. Schön MP, Boehncke W-H. Psoriasis. N Engl J Med. 2005;352:1899-912.

3. Segaert S, Røpke M. The biological rationale for use of vitamin D analogs in combination with corticosteroids for the topical treatment of plaque psoriasis. J Drugs Dermatol. 2013;12:e129-37.

4. World Health Organization. Psoriasis: Sixty seventh World Health Assembly Agenda item 13.5. http://apps.who.int/gb/ ebwha/pdf_files/WHA67/A67_R9-en.pdf. 2014; pp. 1-2.

5. Griffiths CE, Barker JN. Pathogenesis and clinical features of psoriasis. Lancet. 2007;370:263-71.

6. Kimball AB, Gieler U, Linder D, Sampogna F, Warren RB, Augustin M. Psoriasis: is the impairment to a patient's life cumulative? J Eur Acad Dermatol Venereol. 2010;24:989-1004.

7. Gelfand JM, Feldman SR, Stern RS, Thomas J, Rolstad T, Margolis DJ. Determinants of quality of life in patients with psoriasis: a study from the US population. J Am Acad Dermatol. 2004;51:704-8.

8. Menter A, Korman NJ, Elmets CA, et al. Guidelines of care for the management of psoriasis and psoriatic arthritis. Section 3. Guidelines of care for the management and treatment of psoriasis with topical therapies. J Am Acad Dermatol. 2009;60:643-59.

9. Samarasekera E, Sawyer L, Parnham J, Smith CH. Assessment and management of psoriasis: summary of NICE guidance. BMJ. 2012;345:e6712.

10. Fleming C, Ganslandt C, Guenther L, et al. Calcipotriol plus betamethasone dipropionate gel compared with its active components in the same vehicle and the vehicle alone in the treatment of psoriasis vulgaris: a randomised, parallel group, doubleblind, exploratory study. Eur J Dermatol. 2010;20:465-71.

11. McCormack PL. Calcipotriol/betamethasone dipropionate: a review of its use in the treatment of psoriasis vulgaris of the trunk, limbs and scalp. Drugs. 2011;71:709-30.

12. Queille-Roussel C, Hoffmann V, Ganslandt C, Hansen KK. Comparison of the antipsoriatic effect and tolerability of calcipotriol-containing products in the treatment of psoriasis vulgaris using a modified psoriasis plaque test. Clin Drug Investig. 2012;32:613-9.

13. Dumas KJ, Scholtz JR. The psoriasis bio-assay for topical corticosteroid activity. Acta Derm Venereol. 1972;52:43-8.

14. Queille-Roussel C, Clonier F, Olesen M. Short-contact treatment with calcipotriene plus betamethasone dipropionate topical suspension in a psoriasis plaque test model. J Am Acad Dermatol. 2014; 70:AB190.

15. Katz M, Shaikh Z, Maibach HI. ScholtzDumas psoriasis small plaque bioassay. J Dermatolog Treat. 2000;11:15-9.

16. Kvist PH, Svensson L, Hagberg O, Hoffmann V, Kemp K, Røpke MA. Comparison of the effects of vitamin D products in a psoriasis plaque test and a murine psoriasis xenograft model. J Transl Med. 2009;7:107.

17. Bergstrom KG, Arambula K, Kimball AB. Medication formulation affects quality of life: a randomized single-blind study of clobetasol propionate foam $0.05 \%$ compared with a combined program of clobetasol cream $0.05 \%$ and solution $0.05 \%$ for the treatment of psoriasis. Cutis. 2003;72:407-11.

18. Andreassi L, Giannetti A, Milani M. Efficacy of betamethasone valerate mousse in comparison with standard therapies on scalp psoriasis: an open, multicentre, randomized, controlled, crossover study on 241 patients. Br J Dermatol. 2003;148:134-8.

19. Franz TJ, Parsell DA, Halualani RM, Hannigan JF, Kalbach JP, Harkonen WS. Betamethasone valerate foam $0.12 \%$ : a novel vehicle with enhanced delivery and efficacy. Int J Dermatol. 1999;38:628-32.

20. Stein L. Clinical studies of a new vehicle formulation for topical corticosteroids in the treatment of psoriasis. J Am Acad Dermatol. 2005;53:S39-49.

21. Huang X, Tanojo H, Lenn J, Deng CH, Krochmal L. A novel foam vehicle for delivery of topical corticosteroids. J Am Acad Dermatol. 2005;53:S26-38.

22. Basse LH, Olesen M, Lacour JP, Queille-Roussel C. Enhanced in vitro skin penetration and antipsoriatic effect of fixed combination calcipotriol plus betamethasone dipropionate in an innovative foam vehicle. J Invest Dermatol. 2014; 134:S33 (abst 192).

23. Osterberg L, Blaschke T. Adherence to medication. N Engl J Med. 2005;353:487-97.

24. Reich K, Dauden E. Treatment adherence: a hurdle for real-life effectiveness in psoriasis? J Eur Acad Dermatol Venereol. 2014;28(Suppl 2):1-3.

25. Zschocke I, Mrowietz U, Lotzin A, Karakasili E, Reich K. Assessing adherence factors in patients under topical treatment: development of the Topical Therapy Adherence Questionnaire (TTAQ). Arch Dermatol Res. 2014;306:287-97.

26. Bewley A, Page B. Maximizing patient adherence for optimal outcomes in psoriasis. J Eur Acad Dermatol Venereol. 2011;25(Suppl 4):9-14.

27. Devaux S, Castela A, Archier E, et al. Adherence to topical treatment in psoriasis: a systematic literature review. J Eur Acad Dermatol Venereol. 2012;26(Suppl 3):61-7.

28. Dauden E, Bewley A, Lambert J, Girolomoni G, Cambazard F, Reich K. Expert recommendations: the use of the fixed combination calcipotriol and betamethasone dipropionate gel for the topical treatment of psoriasis. J Eur Acad Dermatol Venereol. 2014;28(Suppl 2):22-32. 
29. Zschocke I, Mrowietz U, Karakasili E, Reich K. Non-adherence and measures to improve adherence in the topical treatment of psoriasis. J Eur Acad Dermatol Venereol. 2014;28(Suppl 2):4-9.

30. Lambert J, Hol CW, Vink J. Real-life effectiveness of once-daily calcipotriol and betamethasone dipropionate gel vs. ointment formulations in psoriasis vulgaris: 4- and 12-week interim results from the PRO-long study. J Eur Acad Dermatol Venereol. 2014;28:1723-31.
31. Hol K. Patient preference for topical psoriasis formulations. Poster presented at the EADV Congress, Gothenburg, Sweden. 2010; abst: P572.

32. Housman TS, Mellen BG, Rapp SR, Fleischer AB Jr, Feldman SR. Patients with psoriasis prefer solution and foam vehicles: a quantitative assessment of vehicle preference. Cutis. 2002;70:327-32. 